\title{
HIGH-PERFORMANCE WORKWEAR FOR COAL MINERS IN NORTHERN CHINA: DESIGN AND PERFORMANCE EVALUATION
}

\author{
Ying Ke ${ }^{1}$, Qing Zheng ${ }^{2}$, Faming Wang ${ }^{3, *}$, Min Wang ${ }^{4}$, Yi Wang ${ }^{1}$ \\ 1 School of Design, Jiangnan University, Wuxi, China \\ 2 School of Textile Science and Engineering, Jiangnan University, Wuxi, China \\ 3 School of Architecture and Art, Central South University, Changsha, China \\ 4 Key Laboratory of Clothing Design and Technology, Donghua University, Ministry of Education, Shanghai, China \\ ${ }^{*}$ Corresponding author: E-mail: dr.famingwang@gmail.com
}

\begin{abstract}
:
The design of workwear has significant effects on worker performance. However, the current workwear for coal miners in Northern China is poor in fitness and thermal comfort. In this study, new workwear (NEW) for coal miners was developed with the design features providing better cold protection and movement comfort performance, as compared with a commonly worn workwear (CON). To evaluate the effectiveness of NEW, we conducted human trials which were performed using simulated work movements (i.e., sitting, shoveling, squatting, and crawling) in a climate chamber $\left(10^{\circ} \mathrm{C}, 75 \% \mathrm{RH}\right)$. Physiological measurements and perceptual responses were obtained. The results demonstrated that the local skin temperatures at chest, scapula, thigh, and calf; mean skin temperatures,; and thermal comfort in NEW were significantly higher than those in CON. NEW also exerted an improvement in enhancing movement comfort. We conclude that NEW could meet well with the cold protective and mobility requirements.
\end{abstract}

\section{Keywords:}

Coal mining, workwear, ergonomic design, cold protection, movement comfort, physiological evaluation, perceptual response

\section{Introduction}

Underground coal mining is one of the most hazardous occupations because it is normally performed in a hostile workplace with limited space, narrowed vision, and high dust concentration. Although industrial development has promoted the mechanization of mining production, manual activities are still required for driving, loading, and cleaning activities [1]. Thousands of mining accidents and injuries were reported every year including equipment operating errors, slips, trips, and falls [2-4]. In China, there were over 2,000 deaths resulted from frequent accidents in the coal mining industry every year [5].

It indicates that the improper design of workwear may restrict body movements, impair work performance, and thereby increase expenditure, which can all lead to serious injuries [3, 6]. Zungu [7] also found that when the workwear is poor in fit and comfort, the workers would refuse to wear them, which increases safety and health risks. So far, scholars have conducted ergonomic design and evaluation of varied workwear to improve workers' mobility performance. For example, Lin et al. [8] and Zhai et al. [9] designed a coverall for disaster rescuers whose mobility performance was evaluated by experimental simulations of work tasks, and then analyzed based on the range-of-motion (ROM) of wearers. The wearers' ROM measurement was also effectively used for firefighter ensembles evaluation by Coca et al. [10] and Ciesielska-Wróbel et al. [11]. Further, subjective sensation rating was shown to be valid to obtain information about wearer mobility and comfort in the two studies of chemical/biological protective suit and pear farmers work suit development[12, 13]. Furthermore, movement speed, time consumption, and energy expenditure were also measured for ergonomic evaluation of workwear [14, 15]. Despite many efforts involved in the ergonomic improvement of workwear, only limited research has experimentally examined or improved the mobility performance of workwear for coal miners.

In addition, cold exposure is another problem in the mining industry. Low temperature can occur in shallow underground coal mines during cold weather or in high-latitude areas [16]. Previous research has indicated that the cold environment raises the prevalence of musculoskeletal pain and arthralgia among miners [17]. Jussila et al. [18] evaluated the thermal protective properties of six types of miners' workwear by using questionnaires and a thermal manikin. The results showed that thermal protection was insufficient even though multi-layered fabrics were used.

The protective workwear is essential for the hazardous mining work. Unfortunately, the existing workwear was simply designed and very limited attention has been paid to improve workwear performance. Especially, there is a lack of research to minimize cold stress and provide good mobility performance. To bridge this research gap, this study aimed to develop a new workwear (NEW) for coal miners that meets the requirements of cold protection and body mobility. Wear trials were conducted to 
investigate the thermal and mobility performance of NEW by comparing it with a commercially available and commonly worn workwear (CON). It was hypothesized that the NEW would improve the thermal and movement comfort.

\section{Design of miner workwear}

\subsection{Interview program}

The purpose of this study was to carry out coal miner workwear designs having optimal functional characteristics to meet the demands of cold protection and body mobility. Questionnaires were prepared for this purpose. The questionnaires were distributed to 10 miners from the Xiqu mine (Shanxi, China). A face-to-face interview was also conducted to further know about their needs and preferences regarding the workwear. The results of the questionnaire survey were summarized as follows:

a. Thermal protection and waterproofness are primarily required for the workers who operate in cold and wet work areas. However, the current workwear provides poor thermal protection. Hence, the workers had to put on additional mid-layer clothing to keep warm, which was bulky as well as impair freedom of movement. The moisture from spray equipment soaked the workwear, which reduced comfort and accelerated cooling.

b. Clothing should not restrict movement. Mine work involves a wide range of body movements, including crawling, kneeling, squatting, bending, and arm raising. Improper design of workwear would reduce the comfort of mobility and work efficiency.

c. Higher pocket capacity is required. The pocket capacity should be sufficient for the storage of tools and other accessories, including work gloves, safety lamps, first-aid kits, toolkits, notebooks, and pens.

d. Wearing comfort at the calf regions requires improvement. Some interviewees complained that it was not comfortable enough when tucking the trousers leg areas into the boots. The trousers' structure at calves needs modification.

\subsection{Materials}

The materials of NEW consisted of three kinds of shell fabrics and padded cotton as a thermal liner. All the materials were outsourced from Changzhou Buku Textiles Co. Ltd. (Changzhou, China). The drill fabric and knitted fabrics were made of $100 \%$ cotton, which is considered to be anti-static in highly humid conditions. And the wear-resistant fabric used $98 \%$ cotton and $2 \%$ conductive wires with the waterproof property. The material properties were tested and shown in Table 1.

\subsection{Workwear design}

The NEW consists of a long-sleeved jacket and a pair of trousers, as shown in Figure 1. The jacket length, chest girth, sleeve length, shoulder width, trouser length, waist girth, and hip girth were $78 \mathrm{~cm}, 114 \mathrm{~cm}, 64 \mathrm{~cm}, 47 \mathrm{~cm}, 110 \mathrm{~cm}, 82 \mathrm{~cm}$, and $110 \mathrm{~cm}$, respectively, which fit men in the height range of $175-185 \mathrm{~cm}$. Its total weight was $2.38 \mathrm{~kg}$. Its thermal insulation was estimated to be 1.19 clo [24].

Table 1. Material properties of NEW and CON.

\begin{tabular}{|c|c|c|c|c|c|}
\hline \multirow[b]{2}{*}{ Fabric properties } & \multicolumn{4}{|c|}{ NEW } & \multirow{2}{*}{$\frac{\text { CON }}{\text { Drill fabric }}$} \\
\hline & Drill fabric & Wear-resistant fabric & $\begin{array}{l}\text { Knitted } \\
\text { fabric }\end{array}$ & Padded cotton & \\
\hline Material & $\begin{array}{l}100 \% \\
\text { cotton }\end{array}$ & $\begin{array}{c}98 \% \text { cotton and } 2 \% \text { conductive } \\
\text { wires (water-repellent agent } \\
\text { treated) }\end{array}$ & $100 \%$ cotton & $100 \%$ cotton & $\begin{array}{l}100 \% \\
\text { cotton }\end{array}$ \\
\hline Structure & $\begin{array}{l}3 / 1 \text { twill } \\
\text { weave }\end{array}$ & 2/1 twill weave & Interlock knit & Nonwoven & $\begin{array}{l}2 / 1 \text { twill } \\
\text { weave }\end{array}$ \\
\hline $\begin{array}{l}\text { Warp and weft density } \\
\text { (thread/cm) }\end{array}$ & $45^{\star} 25$ & $50 * 24$ & N/A & $\mathrm{N} / \mathrm{A}$ & $42 * 22$ \\
\hline Thickness (mm) [19] & 0.66 & 0.55 & 0.95 & 3.67 & 0.75 \\
\hline Weight $\left(\mathrm{g} / \mathrm{m}^{2}\right)[20]$ & 282.7 & 238.8 & 398.5 & $\mathrm{~N} / \mathrm{A}$ & 276.1 \\
\hline $\begin{array}{l}\text { Thermal conductivity } \\
\qquad(\mathrm{W} / \mathrm{m} / \mathrm{K})[21]\end{array}$ & 0.069 & 0.043 & 0.089 & $\mathrm{~N} / \mathrm{A}$ & 0.059 \\
\hline $\begin{array}{l}\text { Water vapor permeability } \\
\qquad\left(\mathrm{g} / \mathrm{m}^{2} / \text { day }\right)[22]\end{array}$ & $5,696.0$ & $7,408.7$ & $6,989.7$ & $\mathrm{~N} / \mathrm{A}$ & $2,884.8$ \\
\hline $\begin{array}{l}\text { Air permeability }(\mathrm{mm} / \mathrm{s}) \\
{[23]}\end{array}$ & 147.3 & 44.4 & 46.8 & 28.0 & 31.8 \\
\hline
\end{tabular}

CON, commonly worn workwear; N/A, not applicable; NEW, new workwear. 
The jacket was composed of the main body and a flap over the shoulders. The main body was made of drill fabric. The flap was a three-layer composite, i.e., wear-resistant fabrics used for outer and inner layers and padded cotton as a thermal liner, which was waterproof to avoid being drenched by spray equipment. The flap was fastened to the body using the Velcro fasteners and hence it was easy to don and doff. We designed five pockets (i.e., four in the front and one in the back) to carry tools. The wear-resistant fabric was used in elbow areas to prevent fabric fraying. Moreover, hoop and loop tapes were used at the cuffs and the hem regions to prevent the dust from getting inside.

The drill fabric was used for the trousers. The fit of the trousers was significantly affected by the crotch. Therefore, we increased the crotch depth of the trousers. The waistline at the back was also raised to add extra ease to the center back. The thigh and knee areas used the three-layered cottonpadded materials. The pleats in the knee areas could help the knees to bend easily. The trouser legs are usually tucked into the boots. It would lead to discomfort if too much fabric was piled in the boots. Thus, we decreased the trousers' girths in the lower legs and used elastic knitted fabrics so that it would not be uncomfortably tight.

\section{Methods}

\subsection{Experimental ensembles}

In addition to the NEW described above, a typical and CON was provided by Yulin Coal Industry Co., Ltd. for comparison, as shown in Figure 2. The CON was made of a cotton drill, whose fabric properties were presented in Table 1. Its total weight was $2.41 \mathrm{~kg}$. Its thermal insulation was estimated to be $0.96 \mathrm{clo}$. Apart from the workwear, subjects were also dressed in the same knitted cotton shirt and pants as underclothing and were equipped with a helmet, a pair of gloves, and mining boots.

\subsection{Subjects}

Eleven male students of the university voluntarily participated in this study. The mean and standard deviation of their age,

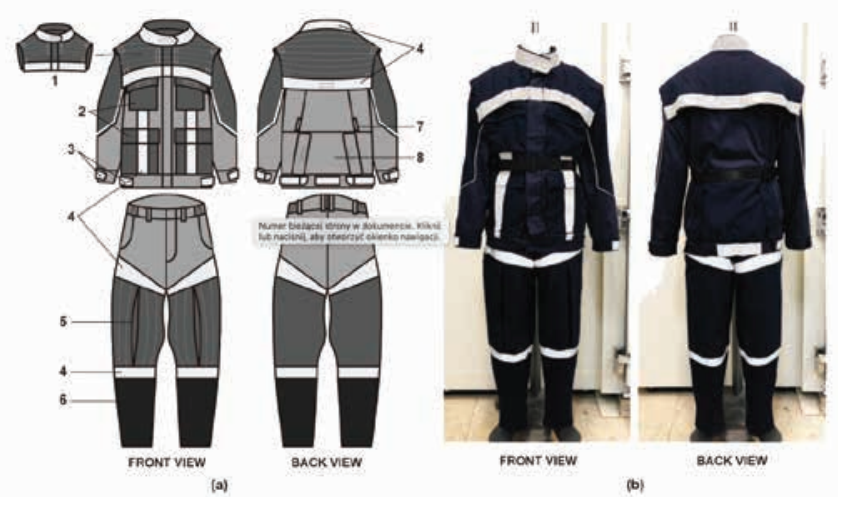

Figure 1. The diagram and photos of newly developed workwear 1-shoulder flap; 2-cargo pockets; 3-hoop and loop tapes; 4retroreflective strips; 5-pleats; 6-knitted lower leg; 7-belt loops; and 8-patch pocket. weight, height, and body mass index (BMI) were $25.9 \pm$ 0.8 years, $77.7 \pm 9.2 \mathrm{~kg}, 1.80 \pm 0.03 \mathrm{~m}$, and $23.87 \pm 2.81 \mathrm{~kg} /$ $\mathrm{m}^{2}$, respectively. Their body dimensions were similar and thus all could fit the same size of the experimental ensembles. They were in good health condition and could bear the load of the trials. Before consenting to participation, they were informed about the purpose and details of this study and signed a consent form. They were also notified that they could quit this study at any time unconditionally. This study strictly followed the Declaration of Helsinki.

\subsection{Test condition}

All trials were conducted in a cold and humid environment using a climate chamber (Espec Corp, Japan). Air temperature of $10.0 \pm 0.5^{\circ} \mathrm{C}, \mathrm{RH}$ of $75 \pm 5 \%$, and air velocity of $0.15 \pm 0.05 \mathrm{~m} / \mathrm{s}$ were maintained. Such a condition was selected to simulate the underground coal mining environment in Northern China [25].

\subsection{Test protocol}

Each subject underwent two wear trials (i.e., NEW and CON) in random order. For each subject, the two trials were conducted at the same time of the days, spaced by at least $24 \mathrm{~h}$, to eliminate the effects of circadian variation. All subjects were asked not to drink coffee, tea, and alcohol 1 day before the test. They were also instructed to not perform any strenuous activities at least $24 \mathrm{~h}$ before each testing.

Upon arrival at the laboratory (room condition: $25^{\circ} \mathrm{C}$, $\mathrm{RH}=60 \%$ ), subjects needed to rest for $30 \mathrm{~min}$ to reach a thermos-neutral state (feel neither warm nor cool and have no sensible sweating). In the meantime, they were briefed about the test procedure and the meanings of the subjective sensation rating scale.

Subjects were then asked to attach the temperature sensor (iButton ${ }^{\circ}$ DS1922L, Maxim Integrated, USA, resolution: $0.0625^{\circ} \mathrm{C}$ ) at 10 skin sites (i.e., forehead, chest, abdomen, scapula, lower back, upper arm, forearm, hand, thigh, and calf) using surgical tapes (3M Co., USA), put on the experimental ensembles, and entered into the climate chamber. During

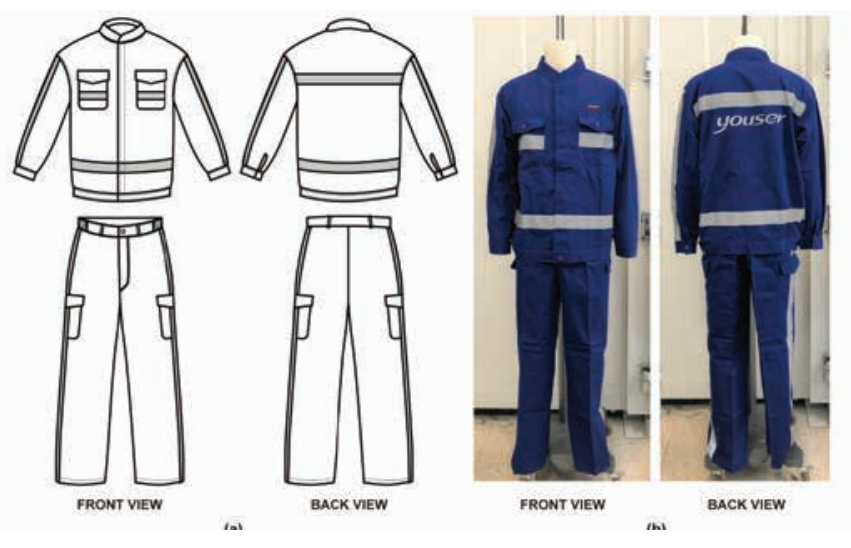

Figure 2. The diagram and photos of CON. CON, commonly worn workwear. 


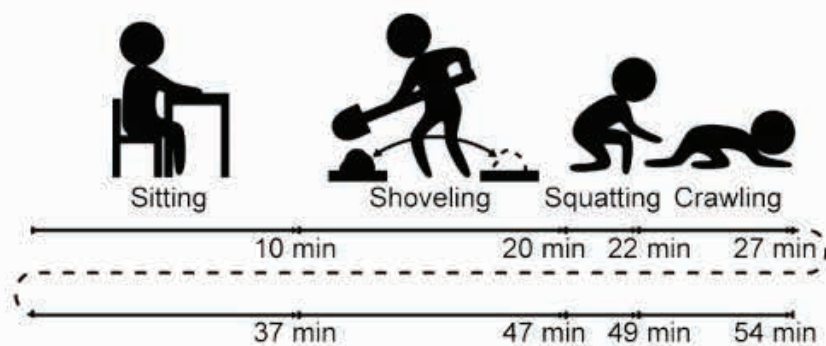

(a)

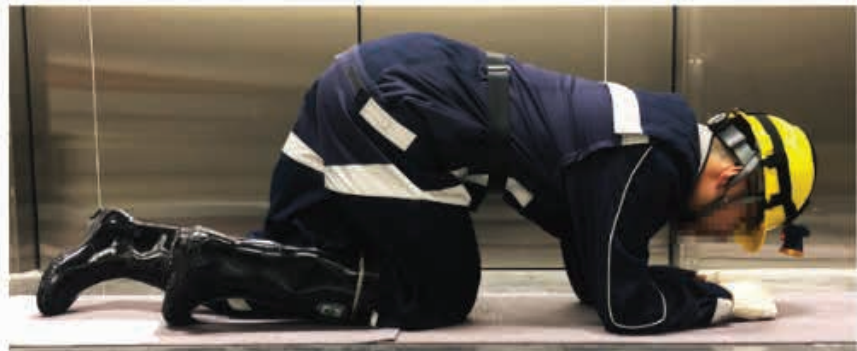

(b)

Figure 3. (a) Diagram of the test procedure and (b) Photo of a subject during the experiment.

the trials, subjects needed to perform a series of movements as shown in Figure 3, which closely resembled the physical movements commonly carried out by miners in their daily work: (i) 10-min sitting, (ii) 10-min shoveling, (iii) 2-min squatting, and (iv) 5 -min crawling at the speed of about $1.5 \mathrm{~km} / \mathrm{h}$. All of these movements were repeated once. Each trial lasted for $54 \mathrm{~min}$ and skin temperatures were recorded for every 1 min throughout the trial. Moreover, subjective thermal comfort and movement comfort were rated immediately after each body movement. A 7-point subjective thermal comfort scale ranging from -3 (very uncomfortably cold), -2 (uncomfortably cold), -1 (slightly uncomfortably cold), 0 (comfortable), +1 (slightly uncomfortably hot), +2 (uncomfortably hot) to +3 (very uncomfortably hot) was used. Meanwhile, the movement comfort for the whole body and five local body parts (i.e., elbows, waist, crotch, knees, and calves) was rated using a 4-point scale ranging from -3 (very uncomfortable), -2 (uncomfortable), -1 (slightly uncomfortable) to 0 (comfortable).

To determine the sweat production and the sweat evaporation efficiency, the semi-nude body weight (i.e., just with briefs), the clothed body weight (i.e., with all pieces of clothing and instrument items), and each clothing piece were weighed before and after trials using a weighing scale (KCC150s, Mettler-Toledo Ag, Switzerland, accuracy: $\pm 1 \mathrm{~g}$ ).

\subsection{Calculations}

The mean skin temperature $\left(T_{\text {skin }}\right)$, the mean torso temperature $\left(T_{\text {torso }}\right)$, and the mean leg temperature $\left(T_{\text {leg }}\right)$ were calculated using the following Eqs (1),-(3), respectively [26].

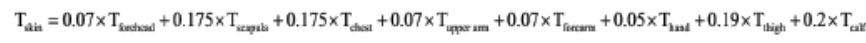

$$
\begin{aligned}
& \mathrm{T}_{\text {torso }}=0.25 \times\left(\mathrm{T}_{\text {chest }}+\mathrm{T}_{\text {abdomen }}+\mathrm{T}_{\text {scapula }}+\mathrm{T}_{\text {lower back }}\right) \\
& \mathrm{T}_{\text {leg }}=0.5 \times\left(\mathrm{T}_{\text {thigh }}+\mathrm{T}_{\text {calf }}\right)
\end{aligned}
$$

where $T_{\text {forehead' }}, T_{\text {scapula }}, T_{\text {chest' }}, T_{\text {upper arm }}, T_{\text {forearm }}, T_{\text {hand }}, T_{\text {thigh, }}, T_{\text {calf }}$ $\mathrm{T}_{\text {abdomen, }}$ and $\mathrm{T}_{\text {lower back }}$ are local skin temperatures at the forehead, scapula, chest, upper arm, forearm, hand, thigh, calf, abdomen, and lower back, respectively.
The sweat production was calculated which is the difference of nude body weight before and after the test. The sweat evaporation efficiency was derived from: (the clothed body weight change/the nude body change) $\times 100 \%$.

\subsection{Statistical analysis}

Data were analyzed using SPSS version 22.0. A two-way repeated measures ANOVA was carried out to determine if there was any significant difference in the local skin temperatures, $T_{\text {skin, }}, T_{\text {torso }}, T_{\text {leg, }}$ and thermal comfort between NEW and CON. A paired samples $t$-test was conducted to compare the movement comfort during each movement (the ratings in the twice repeated processes were averaged), the sweat production, and the sweat evaporation efficiency between NEW and CON. Statistical significance was set to $p<0.05$ (marked as * on the graphs).

\section{Results and discussion}

\subsection{Physiological responses}

\subsubsection{Local skin temperatures}

Figure 4 presents the local skin temperatures at chest, scapula, thigh, and calf. For these four body parts, significantly higher local skin temperatures were observed in NEW than that in CON $(p<0.05)$. In CON, the temperature at chest, scapula, thigh, and calf decreased by $2.9^{\circ} \mathrm{C}, 1.9^{\circ} \mathrm{C}, 4.0^{\circ} \mathrm{C}$, and $3.1^{\circ} \mathrm{C}$, respectively at most. In contrast, for those in NEW, the decrease was about $2.2^{\circ} \mathrm{C}, 1.6^{\circ} \mathrm{C}, 2.0^{\circ} \mathrm{C}$, and $2.6^{\circ} \mathrm{C}$, respectively. However, for the other local body parts (i.e., forehead, abdomen, lower back, upper arm, forearm, and hand), no significant statistical difference in local skin temperatures was observed between the two scenarios.

The previous study has concluded that the cold protective performance of clothing mainly depends on the thermal insulation capability of fabrics [27]. As shown in Table 1, the thermal conductivity of most fabric materials in NEW was higher than that in CON. But the addition of padded cotton (i.e., thermal liner) used in the shoulder flap and thigh areas in NEW contributed to increase in the thermal insulation and thereby diminished the body heat dissipation to the cold environment. This fact was evident from the improvement of local skin temperatures at chest, scapula, and thigh in NEW. 


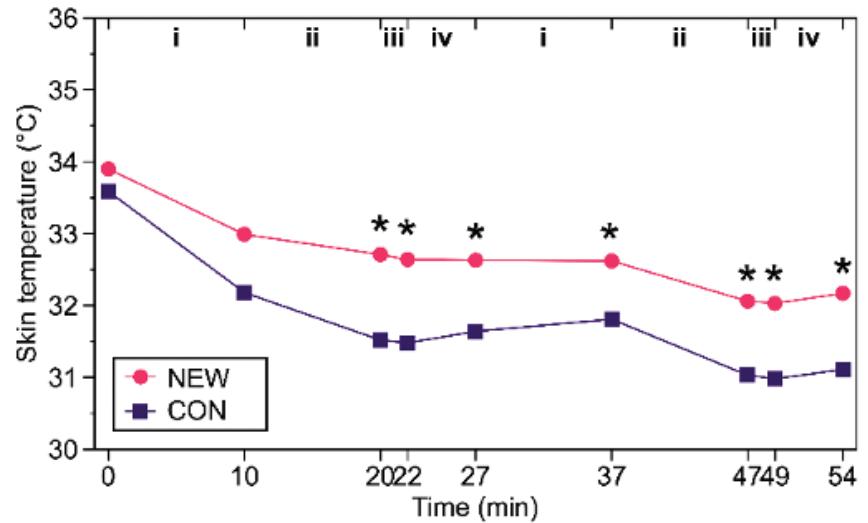

(a) Chest skin temperatures

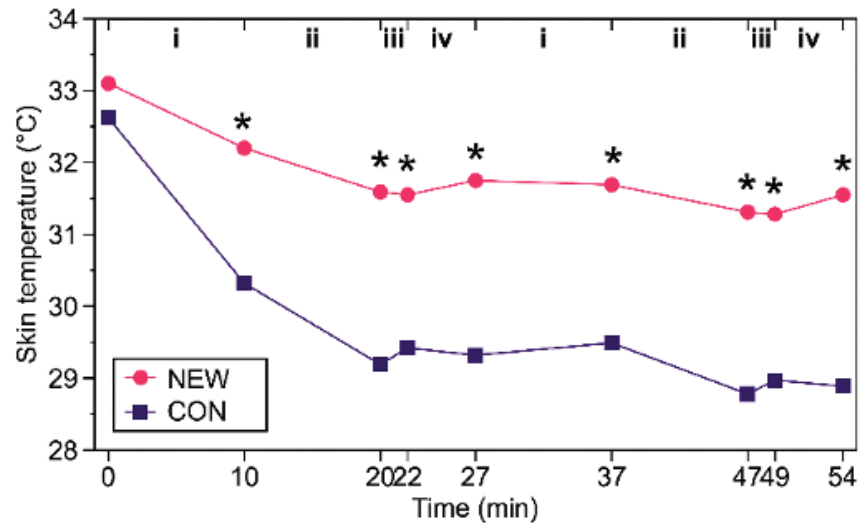

(c) Thigh skin temperatures

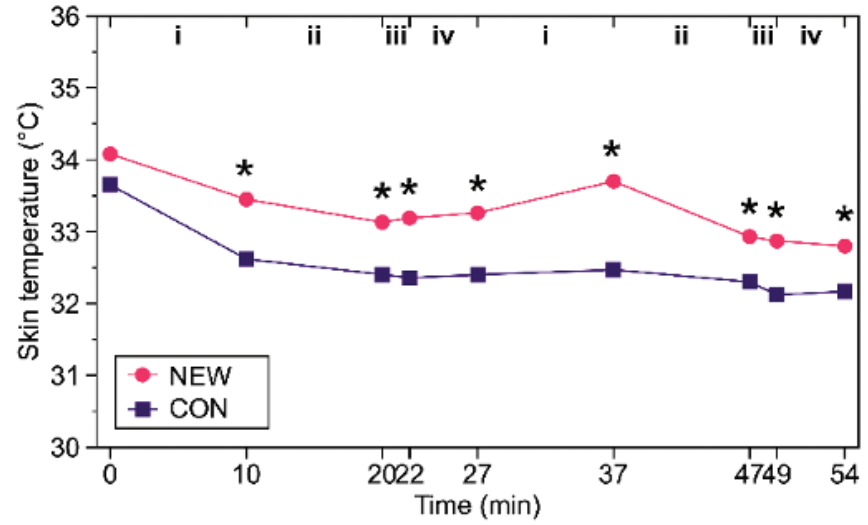

(b) Scapula skin temperatures

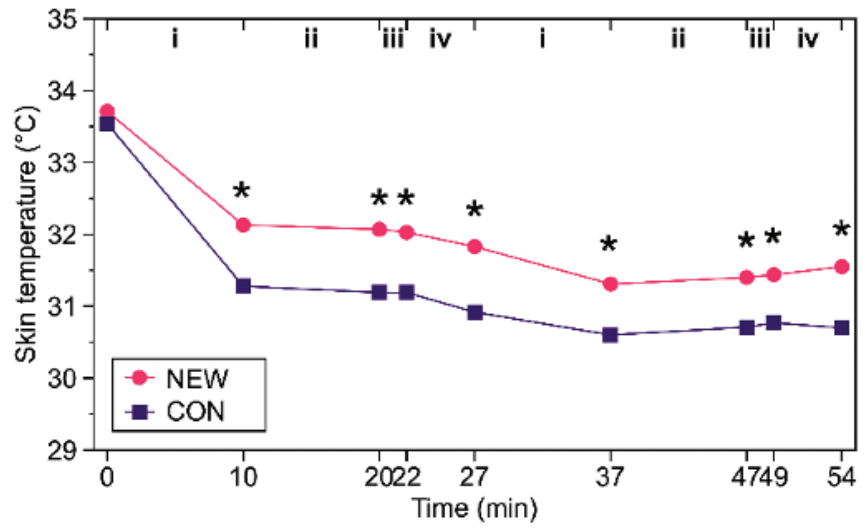

(d) Calf skin temperatures

Figure 4. Local skin temperatures in NEW and CON: (a) Chest skin temperatures; (b) Scapula skin temperatures; (c) Thigh skin temperatures; and (d) Calf skin temperatures. i-sitting period; ii—shoveling period; iii-squatting period; and iv—crawling period. CON, commonly worn workwear; NEW, new workwear.

This fact was consistent with a previous study result that the placing of the insulation had a decisive influence on local skin temperature [28].

\subsubsection{Mean skin, torso, and leg temperatures}

Figure 5 illustrates the comparison of $\mathrm{T}_{\text {skin }}, \mathrm{T}_{\text {torso, }}$ and $\mathrm{T}_{\text {leg }}$ in NEW and CON. Generally, the mean, torso, and leg temperatures in both NEW and CON exhibited a decline in the initial 10-20 min and were relatively stable till the end of the test. The $T_{\text {skin }}$ of NEW had improved by about $1.0^{\circ} \mathrm{C}$ as compared with that of CON, which was within the thermal-neutral range (i.e., $32-34^{\circ} \mathrm{C}$ ) $[29$, 30]. That means the cold protective performance had improved in NEW. Furthermore, the cold protective effectiveness of NEW was more apparent at the lower body (i.e., legs) than at torso. It might be because, in the cold environment, skin temperature in CON decreased much more at limbs that were farther away from the core body than the torso [31]. The thermal liner in NEW reduced the drop of skin temperature at legs and thereby provided a significant improvement in cold protection.

\subsubsection{Sweat production and sweat evaporation efficiency}

The sweat production was $228 \mathrm{~g}$ and $217 \mathrm{~g}$ in NEW and CON, respectively. The sweat evaporation efficiency was $1.8 \%$ and
$1.7 \%$ in NEW and CON, respectively. No statistical difference was observed in sweat production and sweat evaporation efficiency between the two scenarios, indicating that the sweat management properties in NEW needed further improvement.

\subsection{Perceptual responses}

\subsubsection{Thermal comfort}

The thermal comfort in NEW and CON was presented in Figure 6. The thermal comfort in both NEW and CON dropped during $0-10 \mathrm{~min}$ and $27-37 \mathrm{~min}$ (i.e., the sitting periods) and gradually increased during 10-27 $\mathrm{min}$ and 37-54 min (i.e., the shovelling, squatting, and crawling periods), respectively. In NEW, the thermal comfort was rated between -1.4 (i.e., approaching slightly uncomfortably cold) and 0.6 (i.e., approaching slightly uncomfortably hot) throughout the test. In CON, the thermal comfort was rated between -2.1 (i.e., approaching uncomfortably cold) and -0.2 (i.e., approaching neutral). A significant increase was observed in the thermal comfort in NEW after 10th min $(p<0.05)$, compared with CON.

Considering the changes in skin temperature between NEW and $\mathrm{CON}$, it was not surprising to find that the ratings of thermal comfort in NEW were higher than that in CON. However, their evolution was not consistent. When subjects were shoveling, 


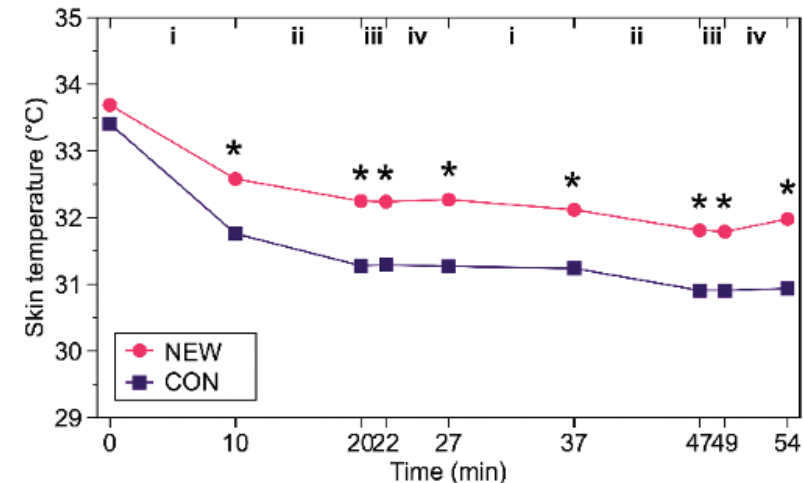

(a) Mean skin temperatures

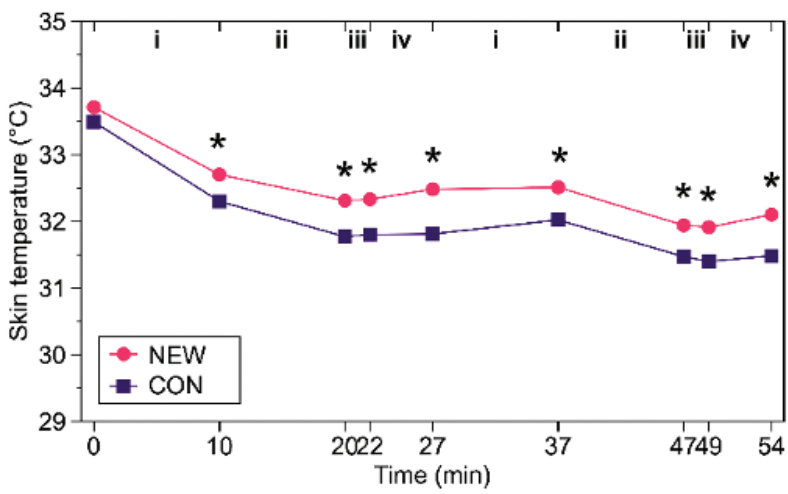

(b) Mean torso temperatures

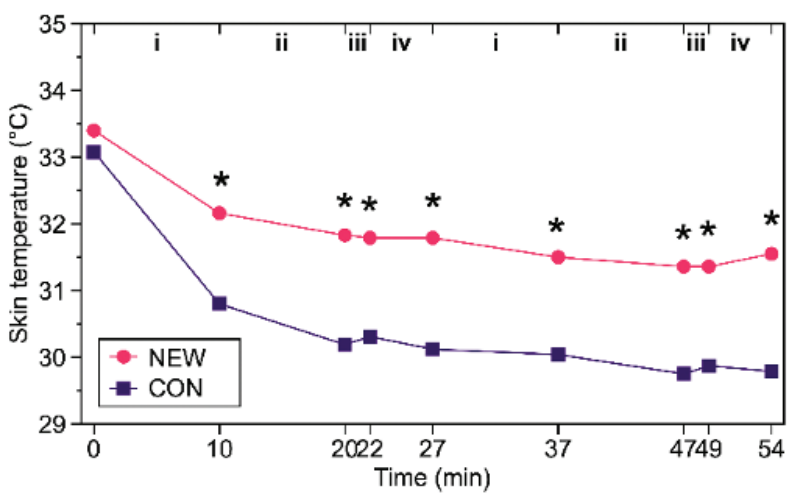

(c) Mean leg temperatures

Figure 5. (a) Mean skin temperatures, (b) mean torso temperatures, and (c) mean leg temperatures. i-sitting period; ii-shovelling period iii-squatting period; and iv—crawling period. CON, commonly worn workwear; NEW, new workwear.

squatting, and crawling, their ratings of thermal comfort gradually increased with time while the skin temperature was relatively low and stable. This result was mainly due to the increased skin wettedness during the dynamic periods. On one hand, skin wettedness contributed to the low skin temperatures. On the other hand, the skin wettedness was more important for thermal comfort perception than the skin temperature [32]. That means although the skin temperatures were relatively low in the current study, the thermal comfort of "uncomfortably hot" sensation was registered when subjects began to sweat during physical activities. Consequently, further improvements were still required to reduce sweat accumulation in clothing and skin surface.

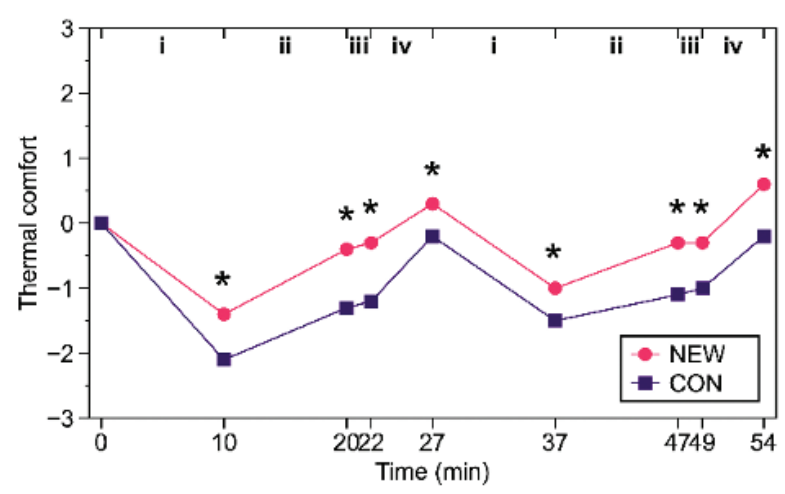

Figure 6. Thermal comfort in NEW and CON. i-sitting period; iishovelling period; iii-squatting period; and iv—crawling period. CON, commonly worn workwear; NEW, new workwear.

\subsubsection{Movement comfort}

Figure 7 presents the movement comfort in NEW and CON at six body parts (i.e., whole body, elbows, waist, crotch, knees, and calves) during four movements (i.e., sitting, shoveling, squatting, and crawling). All points are the mean ratings from the twice repeated movements. During sitting and shovelling periods, NEW and CON exhibited no significant difference in movement comfort, and they were relatively comfortable at all the six tested body parts. During squatting period, the movement comfort ratings in NEW at whole body, waist, crotch, and knee were significantly higher than that in CON (i.e., -0.1 in NEW versus -0.7 in CON, -0.5 in NEW versus -0.8 in CON, -0.4 in NEW versus -1.1 in CON, and -0.2 in NEW versus -1.1 in CON, respectively; $p<0.05$ ). During crawling period, NEW was significantly more comfortable than $\mathrm{CON}$ at whole body, elbows, waist, crotch, and knees (i.e., -1.0 in NEW versus -1.8 in CON, -0.9 in NEW versus -1.4 in CON, 0 in NEW versus -0.7 in CON, -0.2 in NEW versus -1.0 in CON, and -1.5 in NEW versus, -1.9 in CON, respectively; $p<0.05$ ).

The movement comfort increased when subjects were wearing NEW, especially during the squatting and crawling periods. When the workers squat down or crawl forward, body dimensions changed greatly in the leg and buttock areas. Note that the CON was tightly fitted to the body and restricted body movement at knees and crotch. In contrast, the new pattern used in NEW had overcome these problems and enhanced the movement comfort. Further, the movement comfort was also improved at the waist when crawling, because the increased crotch depth, as well as raised waistline, could keep the trousers' back waist from sliding down. In summary, the movement comfort ratings showed that design features in NEW can be expected to have a positive impact on body comfort when miners perform work activities.

\subsection{Limitations}

Some limitations of this study should be acknowledged. Only male students of the university were recruited for clothing ergonomic evaluation, so the findings may not accurately represent coal miners. Manual workers may have different physiological and perceptual responses in a cold environment 


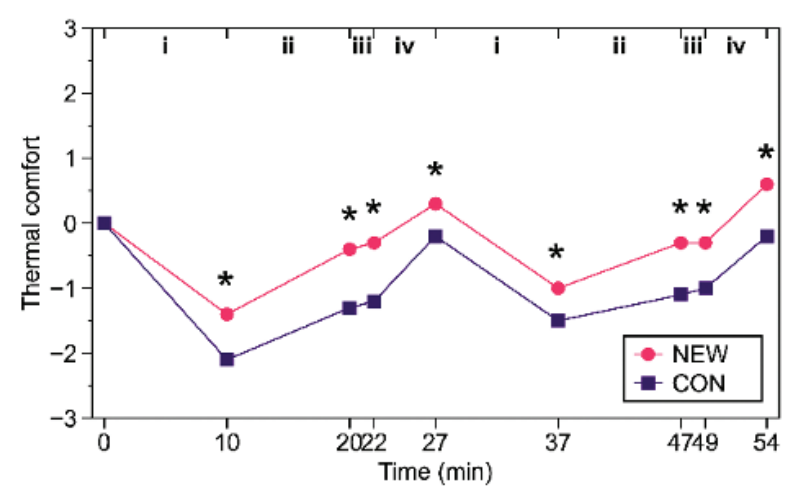

Figure 7. Movement comfort in NEW and CON. CON, commonly worn workwear; NEW, new workwear.

because of the different extent of acclimatization, endurance, and physical fitness. Further, only four movements were used in the experimental protocol (i.e., sitting, shovelling, squatting, and crawling). The differences obtained in subjects' responses between the studied scenarios may be different if a different experimental protocol was used. In future studies, coal miners should be recruited to examine the actual effectiveness of NEW while performing daily mining activities at their workplaces.

\section{CONCLUSIONS}

In this study, NEW for a miner was developed to meet the requirements of cold protection and body mobility in the mining work. The NEW was designed using proper fabrics such as wear-resistant fabric and knitted fabric, which had a good performance in air and moisture permeability. Padded cotton was used as a thermal liner with good insulation properties. The clothing structure of NEW was optimized with improved body mobility, more wearing comfort, and enhanced functionality as compared with CON. The performance of NEW was evaluated for the key requirement of thermal protection and movement comfort through wear trials in simulated work activities. The evaluation results demonstrated that NEW exerts an improvement in alleviating cold strain and enhancing movement comfort as compared with CON. This study has advanced the technology of workwear design for miners. The designs and methods employed in this study are appropriate in developing workwear for other working populations.

\section{Acknowledgements}

This research was funded by the Ministry of Education (MOE) in China Project of Humanities and Social Sciences (No. 20YJCZH063), the China Postdoctoral Science Foundation (No. 2020T130255), and the Open Fund of Key Laboratory of Clothing Design and Technology (Donghua University), Ministry of Education, China (No. KLCDT2020-02).

\section{Author contributions}

The authors Y.K. and Q.Z. contributed equally to this work.

\section{References}

[1] Dobson, J. A., Riddiford-Harland, D. L., Bell, A.F., Steele, J. R. (2018). Are underground coal miners satisfied with their work boots? Applied Ergonomics, 66, 98-104.

[2] Margolis, K. A. (2010). Underground coal mining injury: A look at how age and experience relate to days lost from work following an injury. Safey Science, 48(4), 417-421.

[3] Bell, J. L., Gardner, L. I., Landsittel, D. P. (2000). Slip and fall related injuries in relation to environmental cold and work location in above-ground coal mining operation. American Journal of Industrial Medicine, 38(1), 40-48.

[4] Burgess-Limerick, R. (2007). Reducing injury risks associated with underground coal mining equipment. In: 31st Biennial International Conference of Safety in Mines Research Institutes (2-5 October 2007, Brisbane, Australia).

[5] He, X., Song, L. (2012). Status and future tasks of coal mining safety in China. Safety Science, 50(4), 894-898.

[6] Huck, J. (1991). Restriction to movement in fire-fighter protective clothing evaluation of alternative sleeves and liners. Applied Ergonomics, 22(2), 91-100.

[7] Zungu, L. I. (2013). South African guideline for the selection and provision of personal protective equipment for women in mining. Occupational Health Southern Africa, 19(3), 4-9.

[8] Lin, X., Zhai, L., Zhang, M., Wang, Y., Li, J. (2016). Ergonomic evaluation of protective clothing for earthquake disaster search and rescue team members. International Journal of Clothing Science and Technology, 28(6), 820829.

[9] Zhai, L., Lin, X., Xu, J., Wang, Y., Li, J. (2016). Principles and hierarchy design of protective clothing for earthquake disaster search and rescue team members. International Journal of Clothing Science and Technology, 28(5), 624633.

[10] Coca, A., Roberge, R., Shepherd, A., Powell, J. B., Stull, J. O., et al. (2008). Ergonomic comparison of a chem/bio prototype firefighter ensemble and a standard ensemble. European Journal of Applied Physiology, 104, 351-359.

[11] Ciesielska-Wróbel, I., DenHartog, E., Barker, R. (2017). Measuring the effects of structural turnout suits on firefighter range of motion and comfort. Ergonomics, 60(7), 997-1007.

[12] Barker, R., Deaton, S., Liston, G., Thompson, D. (2010). A $C B$ protective firefighter turnout suit. International Journal of Occupational Safety and Ergonomics, 16(2), 135-152.

[13] Choi, M. S., Ashdown, S. P. (2002). The design and testing of work clothing for female pear farmers. Clothing and Textiles Research Journal, 20(4), 253-263.

[14] Havenith, G., Heus, R. (2004). A test battery related to ergonomics of protective clothing. Applied Ergonomics, 35(1), 3-20.

[15] Murphy, M. M., Patton, J., Mello, R., Bidwell, T., Harp, M. (2001). Energy cost of physical task performance in men and women wearing chemical protective clothing. Aviation, Space, and Environmental Medicine, 72(1), 25-31.

[16] Hilde, F., Julie, R., Øystein, W. (2014). Cold protective clothing and protection for mineworkers in the Barents region-a field study at the open-pit mine at Stjernøya, Norway. In: Proceedings of the 6th European Conference 
on Protective Clothing. (14-16 May 2014, Bruges, Belgium).

[17] Skandfer, M., Talykova, L., Brenn, T., Nilsson, T., Vaktskjold, A. (2014). Low back pain among mineworkers in relation to driving, cold environment and ergonomics. Ergonomics, 57(10), 1541-1548.

[18] Jussila, K., Rissanen, S., Aminoff, A., Wahlström, J., Vaktskjold, A., et al. (2017). Thermal comfort sustained by cold protective clothing in Arctic open-pit mining - A thermal manikin and questionnaire study. Industiral Health, 55(6), 537-548.

[19] ISO 5084:1996. Textiles - determination of thickness of textiles and textile products.

[20] ISO 3801:1977. Textiles - woven fabrics - determination of mass per unit length and mass per unit area.

[21] ASTM D1518-14:2014. Standard test method for thermal resistance of batting systems using a hot plate.

[22] ASTM E96-16:2016. Standard test methods for water vapor transmission of materials.

[23] ASTM D737-18:2018. Standard test method for air permeability of textile fabrics.

[24] ISO 9920:2007. Ergonomics of the thermal environment - estimation of thermal insulation and water vapour resistance of a clothing ensemble.

[25] Yang, X., Han, Q., Pang, J., Shi, X., Hou, D., et al. (2011). Progress of heat-hazard treatment in deep mines. Mine
Science and Technology (China), 21(2), 295-299.

[26] ISO 9886:2004. Ergonomics - Evaluation of thermal strain by physiological measurements.

[27] Matusiak, M., Sybilska, W. (2016). Thermal resistance of fabrics vs. thermal insulation of clothing made of the fabrics. The Journal of the Textile Institute, 107(7), 842848.

[28] Nielsen, R., Nielsen, B. (1984). Influence of skin temperature distribution on thermal sensation in a cool environment. European Journal of Applied Physiology, 53(3), 225-230.

[29] Parsons, K. (2014). Human thermal environments: The effects of hot, moderate, and cold environments on human health, comfort, and performance. Taylor \& Francis (London, UK).

[30] Gagge, A. P., Nishi, Y. (1977). Heat exchange between human skin surface and thermal environment. In: Lee, E. H. K. (Ed.). Handbook of physiology. American Physiological Society (Bethesda, Maryland).

[31] Fournet, D., Ross, L., Voelcker, T., Redortier, B., Havenith, G. (2013). Body mapping of thermoregulatory and perceptual responses of males and females running in the cold. Journal of Thermal Biology, 38(6), 339-344.

[32] Gagge, A. P., Stolwijk, J. A. J., Saltin, B. (1969). Comfort and thermal sensations and associated physiological responses during exercise at various ambient temperatures. Environmental Research, 2, 209-229. 